\title{
Assessment of components of Gingko biloba leaves collected from different regions of China that contribute to its antioxidant effects for improved quality monitoring
}

\author{
$\mathrm{Li} \mathrm{LI}^{1 \dagger}$, Ming-Xu ZHANG ${ }^{2 \dagger}$, Xiao-Yue WANG ${ }^{1}$, Yun-Li YANG ${ }^{1}$, Xue GONG ${ }^{2}$, Cong-Cong WANG², Jin-Fan XU², \\ and Min-Hui LI ${ }^{2 \star}$
}

\begin{abstract}
Ginkgo biloba leaves are commonly used in traditional Chinese medicine. Owing to its wide distribution across China with varying geographical environments and climatic characteristics, G. biloba leaf products have different active ingredients and degrees of activities, which poses a challenge for quality control and standardization. We aimed to identify the key factors contributing to the quality of G. biloba based on assessment of anti-aging and antioxidative components. G. biloba leaf samples collected from 14 different regions in China were analyzed for antioxidant activities by the 2,2'-azino-bis(3-ethylbenzothiazoline6 -sulfonic acid) (ABTS) free radical scavenging assay, and the levels of terpene lactones and flavonoids were quantified by ultraperformance liquid chromatography-tandem mass spectroscopy and high performance liquid chromatography. Correlation analysis attributed the antioxidant activity of G. biloba leaf samples of different origins to isoginkgetin and ginkgetin, which also affected the matrix metalloproteinase- 1 levels of fibroblasts, determined using enzyme-linked immunosorbent assay and reverse transcription-polymerase chain reaction. Therefore, appropriate quality control of a collected G. biloba sample could be achieved by determining the levels of isoginkgetin and ginkgetin as anti-aging and antioxidant components. The results further provide a foundation for the application of G. biloba leaves as an antioxidant raw material.
\end{abstract}

Keywords: antioxidant; anti-aging activity; Ginkgo biloba; ginkgetin; isoginkgetin

Practical Application: Ginkgo biloba leaves can be used as antioxidant raw material.

\section{Introduction}

Ginkgo biloba L. is a large tree with an estimated age of at least 200 million years (Editorial Committee of Chinese Flora of the Chinese Academy of Sciences, 1978). G. biloba leaves have long been used in traditional Chinese medicine owing to its extensive pharmacological action such as scavenging free radicals (Shao et al., 2003; Wang \& Yang, 2001).In vivo assays of the anti-aging effect of $G$. biloba leaf extracts have shown a reduction in the development of skin wrinkles, abnormal hyperplasia of the epidermis, and degradation of elastic fibers during photoaging in $\mathrm{BALB} / \mathrm{c}$ mice. Oxidative stress can change the expression of matrix metalloproteinases (MMPs) and affect the process of aging. Experiments with fibroblasts have shown that G. biloba leaf extracts inhibited induction of the pro-inflammatory factors interleukin (IL)-1, IL-1 $\beta$, IL-6, and tumor necrosis factor-alpha by UVB exposure through the inhibition of extracellular signal-regulated kinase, c-Jun $\mathrm{N}$-terminal kinase, $\mathrm{p} 38$ protein, and reactive oxygen species in the mitogen-activated protein kinase pathway, which ultimately inhibit the increase of MMPs (Chen et al, 2014). Other studies have shown that the main active ingredients of G. biloba leaves are flavonoids and terpene lactone compounds, which reduce oxidative stress and apoptosis to inhibit cell damage (Lin et al, 2008; Yao et al., 2014).
G. biloba leaves are considered a specialty plant material in China with an extensive cultivation area ranging from Shenyang in the northeast to Guangzhou in the south, and growing from altitudes of $40-1000 \mathrm{~m}$ in the east to below $2000 \mathrm{~m}$ (Gong et al., 2008; Guo et al., 2019). Moreover, the components of G. biloba leaves are complex and the most relevant components responsible for its well-established antioxidant activity remain unclear. To clarify these issues, in the present study, we collected G. biloba leaves from 14 different areas of China, which were quantitatively analyzed for five terpene lactones and eight flavonoids along with comparison of the antioxidant activity of the samples. These results can help to identify consistent markers of antioxidant activity despite geographical and environmental variation, which can be used for quality control of G. biloba and to potentially enhance the antioxidant activity of the leaves as a functional food.

\section{Materials and methods}

\subsection{Materials}

2,2'-azino-bis(3-ethylbenzothiazoline-6-sulfonic acid) (ABTS) was obtained from Biodee Biotechnology Co., Ltd. 
(Beijing, China). The MMP-1 ELISA kit (No. I21032323) was purchased from CUSABIO (Wuhan, China). Reference standards of rutin (1), quercetin-3-O- $\beta$-glucoside (2), kaempferol-3-O- $\beta$-Dglucopyranoside (3), isorhamnetin-3-O-glucoside (4), myricetin (5), apigenin (6), isoginkgetin (7), ginkgetin (8), ginkgolide A (9), ginkgolide B (10), ginkgolide C (11), ginkgolide J (12), and bilobalide (13) were purchased from Beijing Simianti Tech. Co., Ltd. (Beijing, China). Human dermal fibroblasts (HDFs) were purchased from the Cell Bank of the Shanghai Institutes for Biological Sciences, Chinese Academy of Sciences. The XGB-40-B laboratory water purifier was purchased from Shenyang Xinjie Technology Co., Ltd. (Shenyang, China). The Ultimate 3000 HPLC-UV system and the TSQ Altis mass spectrometer were purchased from Thermo Fisher Scientific (Shanghai, China). The TSK-GEL ODS column (4.6 mm $\times 25 \mathrm{~cm}$ ) was purchased from TOSOH (Shanghai, China) and the ACQUITY UPLC BEH C18 column $(2.1 \times 100 \mathrm{~mm}, 1.7 \mu \mathrm{m})$ was purchased from Waters (Shanghai, China).

\subsection{G. biloba leaves collection}

Based on a fieldwork investigation of planted resources and collected samples, G. biloba leaves from 14 regions across China were selected for antioxidant analysis, and the 13 chemical constituents described above were quantified in each sample. Detailed sample location information is shown in Table 1, which is in the supplemental file, and the structures of the five terpene lactones and eight flavonoids are shown in Figure 1.

\subsection{Extraction of G. biloba leaves}

G. biloba leaves $(10 \mathrm{~g})$ were crushed and $200 \mathrm{~mL} 95 \%$ ethanol $(\mathrm{w} / \mathrm{v}, 1: 20)$ was added. The mixture was extracted for $1 \mathrm{~h}$ at $50^{\circ} \mathrm{C}$ by ultrasonication three times, and the filtered supernatants were concentrated and dried. The G. biloba leaf extracts were further diluted to concentrations of $0.03,0.06,0.12,0.25,0.5$, and
$1.0 \mathrm{mg} / \mathrm{mL}$ with anhydrous ethanol to analyze the 13 compounds of interest and conduct the ABTS free radical scavenging assay.

\subsection{Flavonoid quantification by high performance liquid chromatography/diode-array detection}

The chromatographic analysis was conducted under the following conditions: mobile phase, water with $0.2 \%$ phosphoric acid (A) and acetonitrile (B); flow rate, $0.5 \mathrm{~mL} / \mathrm{min}$; column temperature, $30^{\circ} \mathrm{C}$; injection volume, $5.0 \mu \mathrm{L}$; and detection wavelength, $270 \mathrm{~nm}$. The elution gradient was as follows: 85-75\% (A) at 0-25 $\mathrm{min}, 75-70 \%(\mathrm{~A})$ at $25-40 \mathrm{~min}, 70-50 \%(\mathrm{~A})$ at $40-45 \mathrm{~min}, 50-40 \%(\mathrm{~A})$ at $45-55 \mathrm{~min}, 40-30 \%(\mathrm{~A})$ at $55-70 \mathrm{~min}$, and $30-30 \%(\mathrm{~A})$ at $70-75 \mathrm{~min}$ (Wang et al., 2020).

We accurately weighed an appropriate amount of the references rutin (1), quercetin-3-O- $\beta$-glucoside (2), kaempferol 3-O- $\beta$-D-glucopyranoside (3), isorhamnetin-3-O-glucoside (4), myricetin (5), apigenin (6), isoginkgetin (7), and ginkgetin (8), which were established as mix reference solutions with concentrations of $12,6,12,12,12,6,12$, and $12 \mu \mathrm{g} / \mathrm{mL}$, respectively. We then analyzed the prepared mixed standards according to the chromatographic conditions described above and constructed the calibration curve for each reference.

Terpene lactone quantification by ultra-performance liquid chromatography-tandem mass spectrometry (UPLC-MS/MS)

The TSQ Altis mass spectrometer (Thermo Fisher) was used for mass spectrometric detection with the following conditions: ion source type, heated electrospray ionization; detection mode, selected reaction monitoring (SRM); ion, $3500 \mathrm{~V}$; negative ion, $3500 \mathrm{~V}$; sheath gas, $35 \mathrm{Arb}$; auxiliary gas, $10 \mathrm{Arb}$; vaporizer temperature, $350^{\circ} \mathrm{C}$; ion transfer tube temperature, $300^{\circ} \mathrm{C}$; CID gas, 2 mTorr. The information for the SRM mode of the reference compounds is provided in Table 2, which is in the supplemental file.

Table 1. The collection location G. biloba leaves resource.

\begin{tabular}{cccc}
\hline No. & Origin & Latitude & Longitude \\
\hline 1 & Anguo & $\mathrm{N} 38^{\circ} 42^{\prime}$ & $\mathrm{E} 115^{\circ} 33^{\prime}$ \\
2 & Liaoning & $\mathrm{N} 38^{\circ} 43^{\prime}-43^{\circ} 26^{\prime}$ & $\mathrm{E} 118^{\circ} 53^{\prime}-125^{\circ} 46^{\prime}$ \\
3 & Xuzhou & $\mathrm{N} 33^{\circ} 43^{\prime}-34^{\circ} 58^{\prime}$ & $\mathrm{E} 116^{\circ} 22^{\prime}-118^{\circ} 40^{\prime}$ \\
4 & Jinan & $\mathrm{N} 6^{\circ} 35^{\prime}-36^{\circ} 40^{\prime}$ & $\mathrm{E} 116^{\circ} 54^{\prime}-117^{\circ} 02^{\prime}$ \\
5 & Nanjing & $\mathrm{N} 31^{\circ} 14^{\prime}-32^{\circ} 37^{\prime}$ & $\mathrm{E} 118^{\circ} 22^{\prime}-119^{\circ} 14^{\prime}$ \\
6 & Sichuan & $\mathrm{N} 26^{\circ} 03^{\prime}-34^{\circ} 19^{\prime}$ & $\mathrm{E} 97^{\circ} 21^{\prime}-108^{\circ} 12^{\prime}$ \\
7 & Hubei & $\mathrm{N} 29^{\circ} 01^{\prime}-33^{\circ} 6^{\prime}$ & $\mathrm{E} 108^{\circ} 21^{\prime}-116^{\circ} 07^{\prime}$ \\
8 & Tancheng & $\mathrm{N} 34^{\circ} 22^{\prime}-34^{\circ} 56^{\prime}$ & $\mathrm{E} 118^{\circ} 05^{\prime}-118^{\circ} 31^{\prime}$ \\
10 & Shaoyang & $\mathrm{N} 25^{\circ} 58^{\prime}-27^{\circ} 40^{\prime}$ & $\mathrm{E} 109^{\circ} 49^{\prime}-112^{\circ} 57^{\prime}$ \\
11 & Xinjiang & $\mathrm{N} 34^{\circ} 22^{\prime}-49^{\circ} 10^{\prime}$ & $\mathrm{E} 73^{\circ} 40^{\prime}-96^{\circ} 23^{\prime}$ \\
12 & Lianyungang & $\mathrm{N} 33^{\circ} 59^{\prime}-35^{\circ} 07^{\prime}$ & $\mathrm{E} 118^{\circ} 24^{\prime} \sim 119^{\circ} 48^{\prime}$ \\
13 & Hebei & $\mathrm{N} 36^{\circ} 05^{\prime}-42^{\circ} 40^{\prime}$ & $\mathrm{E} 113^{\circ} 27^{\prime}-119^{\circ} 50^{\prime}$ \\
\hline
\end{tabular}


<smiles>CC[C@H]1OC(OCC2OC(Oc3oc4cc(O)cc(O)c4c(=O)c3-c3cc(C)c(O)c(O)c3)[C@H](O)[C@H](O)[C@H]2O)[C@H](O)[C@@H](O)[C@H]1O</smiles><smiles>COc1cc(-c2oc3cc(O)cc(O)c3c(=O)c2O[C@@H]2O[C@H](CO)[C@@H](O)[C@H](O)[C@H]2O)ccc1O</smiles><smiles>COc1ccc(-c2cc(=O)c3c(O)cc(O)c(-c4cc(-c5cc(=O)c6c(O)cc(O)cc6o5)ccc4OC)c3o2)cc1</smiles>

7<smiles>COc1cc(O)c2c(=O)cc(-c3ccc(OC)c(-c4c(O)cc(O)c5c(=O)cc(-c6ccc(O)cc6)oc45)c3)oc2c1</smiles>

6<smiles>O=c1c(O)c(-c2cc(O)c(O)c(O)c2)oc2cc(O)cc(O)c12</smiles>

5<smiles>O=c1c(OC2OC(CO)[C@@H](O)[C@H](O)[C@H]2O)c(-c2ccc(O)c(O)c2)oc2cc(O)cc(O)c12</smiles>

2

8

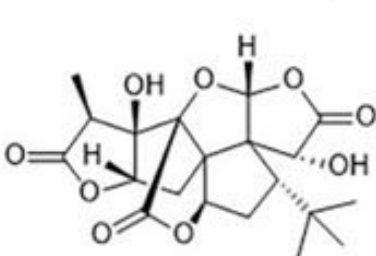

9<smiles>O=c1cc(-c2ccc(O)cc2)oc2cc(O)cc(O)c12</smiles>

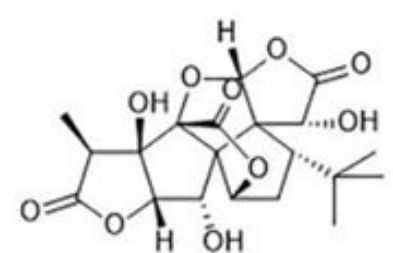

10

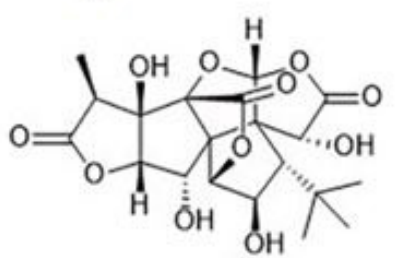

11

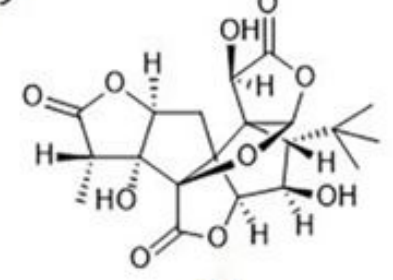

12

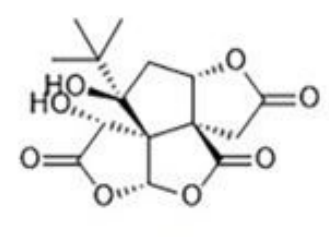

13

Figure 1. The structure of eight flavonoids in G. biloba leaves: rutin (1), quercetin-3-O- $\beta$-glucoside (2), kaempferol-3-O- $\beta$-D-glucopyranoside (3), isorhamnetin-3-O-glucoside (4), myricetin (5), apigenin (6), isoginkgetin (7) and ginkgetin(8); The structure of five lactones in G. biloba leaves: ginkgolide A (9), ginkgolide B (10), ginkgolide C (11), ginkgolide J (12), and bilobalide (13). 
Li et al.

Table 2. Determination of eight flavonoids and five lactones in G. biloba leaf ( $\mathrm{n}=3, x,- \pm \mathrm{s})$.

\begin{tabular}{|c|c|c|c|c|c|c|c|c|c|c|c|c|c|}
\hline Origin & Rutin & $\begin{array}{l}\text { Quercetin- } \\
\text { 3-O- } \beta- \\
\text { glucoside }\end{array}$ & $\begin{array}{c}\text { Kaempferol- } \\
\text { 3-O- } \beta \text {-D- } \\
\text { glucopyranoside }\end{array}$ & $\begin{array}{l}\text { Isorhamnetin- } \\
\text { 3-O-glucoside }\end{array}$ & Myricetin & Apigenin & Isoginkgetin & Ginkgetin & Ginkgolide A & Ginkgolide B & Ginkgolide C & Ginkgolide J & Bilobalide \\
\hline 1 & $5.28 \pm 0.05$ & $1.70 \pm 0.003$ & $2.49 \pm 0.06$ & $2.30 \pm 0.02$ & $2.70 \pm 0.03$ & $1.49 \pm 0.01$ & $6.34 \pm 0.06$ & $5.09 \pm 0.08$ & $0.82 \pm 0.04$ & $1.52 \pm 0.09$ & $1.27 \pm 0.02$ & $0.22 \pm 0.03$ & $8.62 \pm 0.11$ \\
\hline 2 & $6.80 \pm 0.01$ & $1.93 \pm 0.003$ & $2.41 \pm 0.00$ & $2.61 \pm 0.01$ & $4.00 \pm 0.02$ & $1.45 \pm 0.02$ & $6.05 \pm 0.04$ & $5.29 \pm 0.01$ & $1.78 \pm 0.04$ & $1.76 \pm 0.04$ & $1.06 \pm 0.01$ & $0.43 \pm 0.02$ & $8.91 \pm 0.42$ \\
\hline 3 & $8.68 \pm 0.19$ & $2.48 \pm 0.03$ & $2.53 \pm 0.18$ & $2.67 \pm 0.01$ & $6.03 \pm 0.05$ & - & $7.07 \pm 0.14$ & $6.63 \pm 0.10$ & $4.18 \pm 0.04$ & $2.77 \pm 0.29$ & $1.81 \pm 0.53$ & $0.92 \pm 0.02$ & $22.89 \pm 0.25$ \\
\hline 4 & $6.44 \pm 0.03$ & $1.89 \pm 0.01$ & $2.57 \pm 0.17$ & $2.45 \pm 0.06$ & $3.72 \pm 0.05$ & $1.48 \pm 0.03$ & $6.63 \pm 0.03$ & $5.95 \pm 0.01$ & $1.18 \pm 0.11$ & $1.64 \pm 0.23$ & $1.05 \pm 0.16$ & $0.27 \pm 0.09$ & $7.85 \pm 0.16$ \\
\hline 5 & $4.27 \pm 0.08$ & $1.36 \pm 0.02$ & - & $2.39 \pm 0.03$ & $4.01 \pm 0.06$ & $1.90 \pm 0.01$ & $6.33 \pm 0.07$ & $5.83 \pm 0.08$ & $1.93 \pm 0.08$ & $2.16 \pm 0.19$ & $2.05 \pm 0.07$ & $0.34 \pm 0.13$ & $11.43 \pm 0.45$ \\
\hline 6 & $5.15 \pm 0.01$ & $1.60 \pm 0.13$ & - & $2.37 \pm 0.01$ & $3.40 \pm 0.01$ & $1.64 \pm 0.01$ & $6.09 \pm 0.01$ & $5.36 \pm 0.01$ & $1.61 \pm 0.03$ & $2.18 \pm 0.13$ & $1.82 \pm 0.08$ & $0.40 \pm 0.13$ & $10.75 \pm 0.06$ \\
\hline 7 & $7.28 \pm 0.01$ & $2.14 \pm 0.01$ & $2.60 \pm 0.01$ & $3.29 \pm 0.07$ & $4.72 \pm 0.01$ & $1.31 \pm 0.00$ & $5.70 \pm 0.02$ & $6.37 \pm 0.01$ & $2.38 \pm 0.02$ & $2.98 \pm 0.23$ & $3.54 \pm 0.01$ & $0.66 \pm 0.05$ & $18.86 \pm 0.13$ \\
\hline 8 & $4.20 \pm 0.08$ & $1.38 \pm 0.01$ & - & - & $3.30 \pm 0.04$ & $1.49 \pm 0.01$ & $5.76 \pm 0.06$ & $5.96 \pm 0.07$ & $2.37 \pm 0.08$ & $2.77 \pm 0.15$ & $3.12 \pm 0.08$ & $0.54 \pm 0.15$ & $11.83 \pm 0.29$ \\
\hline 9 & $4.15 \pm 0.03$ & $1.77 \pm 0.02$ & $2.40 \pm 0.02$ & $2.43 \pm 0.02$ & $5.31 \pm 0.04$ & - & $2.78 \pm 0.07$ & $4.45 \pm 0.06$ & $2.53 \pm 0.14$ & $2.02 \pm 0.16$ & $2.17 \pm 0.06$ & $0.38 \pm 0.03$ & $21.92 \pm 0.28$ \\
\hline 10 & $7.52 \pm 0.28$ & $2.51 \pm 0.01$ & $2.62 \pm 0.01$ & $2.75 \pm 0.03$ & $5.20 \pm 0.01$ & $1.56 \pm 0.01$ & $8.03 \pm 0.01$ & $6.36 \pm 0.01$ & $2.21 \pm 0.19$ & $2.33 \pm 0.16$ & $1.99 \pm 0.04$ & $0.52 \pm 0.16$ & $11.15 \pm 0.19$ \\
\hline 11 & $4.94 \pm 0.01$ & $2.35 \pm 0.01$ & $2.78 \pm 0.01$ & $2.70 \pm 0.02$ & $3.63 \pm 0.01$ & $1.31 \pm 0.01$ & $7.56 \pm 0.02$ & $4.98 \pm 0.02$ & $1.37 \pm 0.11$ & $2.14 \pm 0.28$ & $1.41 \pm 0.03$ & $0.43 \pm 0.03$ & $10.62 \pm 0.53$ \\
\hline 12 & $5.72 \pm 0.02$ & $2.01 \pm 0.01$ & $2.65 \pm 0.01$ & $2.75 \pm 0.01$ & $3.57 \pm 0.02$ & - & $7.16 \pm 0.04$ & $6.13 \pm 0.03$ & $1.01 \pm 0.03$ & $1.74 \pm 0.08$ & $1.82 \pm 0.01$ & $0.30 \pm 0.12$ & $11.04 \pm 0.68$ \\
\hline 13 & $5.16 \pm 0.01$ & $1.65 \pm 0.01$ & $2.51 \pm 0.01$ & $2.34 \pm 0.01$ & $3.07 \pm 0.01$ & $1.51 \pm 0.02$ & $5.62 \pm 0.04$ & $5.83 \pm 0.09$ & $0.93 \pm 0.10$ & $1.69 \pm 0.08$ & $1.29 \pm 0.07$ & $0.27 \pm 0.02$ & $10.37 \pm 0.25$ \\
\hline 14 & $6.94 \pm 0.01$ & $2.19 \pm 0.002$ & - & $2.63 \pm 0.01$ & $16.52 \pm 0.01$ & $1.15 \pm 0.01$ & $5.74 \pm 0.04$ & $4.81 \pm 0.01$ & $7.55 \pm 0.19$ & $3.60 \pm 0.14$ & $4.45 \pm 0.75$ & $1.42 \pm 0.08$ & $48.95 \pm 1.45$ \\
\hline
\end{tabular}

“-"means no detection.

For chromatography, the references were separated with the ACQUITY UPLC BEH C18 column $(2.1 \times 100 \mathrm{~mm}, 1.7 \mu \mathrm{m})$, using acetonitrile (A) and $0.1 \%$ formic acid solution (B) as the mobile phase with a gradient of $10 \% \mathrm{~A}$ at 0-10 min. The flow rate was $0.3 \mathrm{~mL} / \mathrm{min}$, the column temperature was set at $30^{\circ} \mathrm{C}$, and the injection volume was $2.0 \mu \mathrm{L}$.

We accurately weighed an appropriate amount of the standard references ginkgolide A, B, C, and J, and bilobalide to prepare the mixed reference solutions at five concentrations of $8.6,15.7,3.8,3.9$, and $1.6 \mu \mathrm{g} / \mathrm{mL}$. We then constructed each calibration curve using the mixed standard reference concentrations according to the UPLC-MS/MS conditions described above. The limit of detection and limit of quantitation were determined based on signal-to-noise ratios of 3:1 and $10: 1$, respectively.

\subsection{Determination of ABTS free radical scavenging activity}

We thoroughly mixed $0.2 \mathrm{~mL}$ of the different concentrations of each sample with $0.8 \mathrm{~mL}$ ABTS solution and allowed the mixture to react in the dark for $30 \mathrm{~min}$ at $25^{\circ} \mathrm{C}$. The absorbance of the mixture was measured at $734 \mathrm{~nm}$ using $0.2 \mathrm{~mL}$ distilled water as the blank control, and the clearance rate was calculated according to the following formula (Equation 1):

Clearance rate $(\%)=\left[\left(A_{0}-A\right) / A_{0}\right] \times 100 \%$

where $\mathrm{A}_{0}$ is absorbance of the control and $\mathrm{A}$ is absorbance of the sample

\subsection{Correlation between antioxidant activity and components of $G$. biloba extracts}

The Pearson correlation coefficient of the half-maximal inhibitory concentration $\left(\mathrm{IC}_{50}\right)$ value of the antioxidant index (clearance rate) measured using the ABTS assay and the 13 components of the extract was calculated using Statistical Package for the Social Sciences (SPSS) version 25. Student's $t$-test was used to determine the active components that were significantly related to the $\mathrm{IC}_{50}$ (Xu \& Zhang, 2017).

\subsection{Cell culture and cell viability assay}

HDFs were cultured in Dulbecco's modified Eagle medium (DMEM) supplemented with $10 \%$ fetal bovine serum (FBS; BioWhittaker, Walkersville, MD, USA) and $1 \%$ penicillin-streptomycin (Gibco BRL, NY, USA) at $37{ }^{\circ} \mathrm{C}$ in a humidified atmosphere containing $5 \% \mathrm{CO}_{2}$. HDFs were seeded at a density of $1 \times 10^{4}$ cells/well in 96-well plates for $24 \mathrm{~h}$. The medium was removed, the cells were washed with sterilized phosphate-buffered saline (PBS), and the buffer was replaced with the medium containing the samples diluted to varying concentrations $(0.05,0.1,0.2$, and $0.4 \mathrm{mg} / \mathrm{mL})$. After $24-\mathrm{h}$ incubation, the medium was removed, the cells were washed with sterilized PBS, and HDF proliferation was measured using the Cell Counting Kit (CCK)-8 assay after diluting the CCK-8 solution 1:10. The absorbance of the cell suspension was then read at $450 \mathrm{~nm}$ using a microplate reader. The cell viability is expressed as a percentage of that of the negative control, and each sample was assayed using three replicates (Lee et al., 2006).

\subsection{Enzyme-linked immunosorbent assay (ELISA) of MMP-1 levels}

HDFs were seeded in six-well plates $\left(5 \times 10^{5}\right.$ cells $\left./ \mathrm{mL}\right)$ with DMEM containing 10\% FBS for $24 \mathrm{~h}$, and then the medium was replaced with serum-free medium containing the test samples. After incubation for $24 \mathrm{~h}$, the supernatant was collected from each well and MMP-1 levels in the supernatant were quantified by ELISA according to the instructions of the kit (Du et al., 2017). 


\subsection{Reverse transcription-quantitative polymerase chain reaction ( $R T-P C R)$}

HDFs were seeded in six-well plates $\left(1.8 \times 10^{5}\right.$ cells/well $)$ and incubated overnight at $37^{\circ} \mathrm{C}$ in a $5 \% \mathrm{CO}$ incubator. After treatment with the samples for $24 \mathrm{~h}$, HDF cells were harvested, total RNA was extracted using TRIzol RNA extraction reagent, and then cDNA was synthesized from the total RNA. The $M M P 1$ primer sequences used to amplify the desired cDNA were forward, 5'-AAGGTGGACCAACAATTTCAGA-3' and reverse, 5'-TGAAGGTGTAGCTAG GGTACATCAA-3'. Fluorescence quantitative PCR detection was then performed, and each sample was assayed in triplicate.

\subsection{Statistical analysis}

SPSS version 25.0 was used for all statistical analyses. Each experiment was repeated three times, and the data are expressed as the mean \pm standard deviation. Data between groups were compared using analysis of variance, and $P<0.01$ was considered statistically significant.

\section{Results}

\subsection{Quantification of flavonoids and terpene lactones in G. biloba leaves}

UPLC-MS/MS analysis of lactones in the 14 G. biloba leaf samples showed some differences in the levels of rutin (1), quercetin-3-O- $\beta$-glucoside (2), kaempferol-3-O- $\beta$-d-glucopyranoside (3), isorhamnetin-3-O-glucoside (4), myricetin (5), apigenin (6), isoginkgetin (7), ginkgetin (8), ginkgolide A (9), ginkgolide B (10), ginkgolide C (11), ginkgolide J (12), and bilobalide (13). The results of the HPLC analysis and UPLC-MS/MS analysis are shown in Table 2. Part of the HPLC analysis results and the standard diagram of UPLC-MS/MS analysis is shown in Figure 2.

\subsection{Determination of antioxidant activity}

There were also differences in the ABTS scavenging abilities of $G$. biloba leaf extracts collected from different areas (Table 3). Many oxidative stress-related diseases and physiological processes such as aging are caused by the accumulation of free radicals in the human body. Flavonoids and terpene lactones from G. biloba leaf extracts are reported as good antioxidants (Kingsley et al., 2019; Qiu et al., 2017). Therefore, we further determined the specific components contributing to the variation in antioxidant properties of G. biloba leaves of different regions.

\subsection{Correlation between the $\mathrm{IC}_{50}$ value determined using ABTS and active components}

Analysis of the 13 compounds in G. biloba leaf extracts from 14 different regions and their antioxidant activity (Table 4) demonstrated a significant correlation between the levels of isoginkgetin and ginkgetin and the $\mathrm{IC}_{50}$ value $(\mathrm{r}=-0.761$ and -0.703 , respectively; both $P<0.01$ ). The lower the $\mathrm{IC}_{50}$, the stronger the antioxidant activity, which explains the negative correlation. Therefore, these two flavonoids were considered to be mainly responsible for the antioxidant property of G. biloba leaves.

\subsection{Effect of isoginkgetin and ginkgetin on HDF viability}

Pretreatment of HDFs for $24 \mathrm{~h}$ with two different concentrations $(0.1$ and $0.2 \mathrm{mg} / \mathrm{mL})$ of isoginkgetin and ginkgetin showed no significant differences in cell viability compared with that of the control group $(P>0.05)$. Furthermore, pretreatment of HDF cells with the two compounds at concentrations of 0.1 and $0.2 \mathrm{mg} / \mathrm{mL}$ caused no cytotoxicity: In $0.1 \mathrm{mg} / \mathrm{mL}$, isoginkgetin and

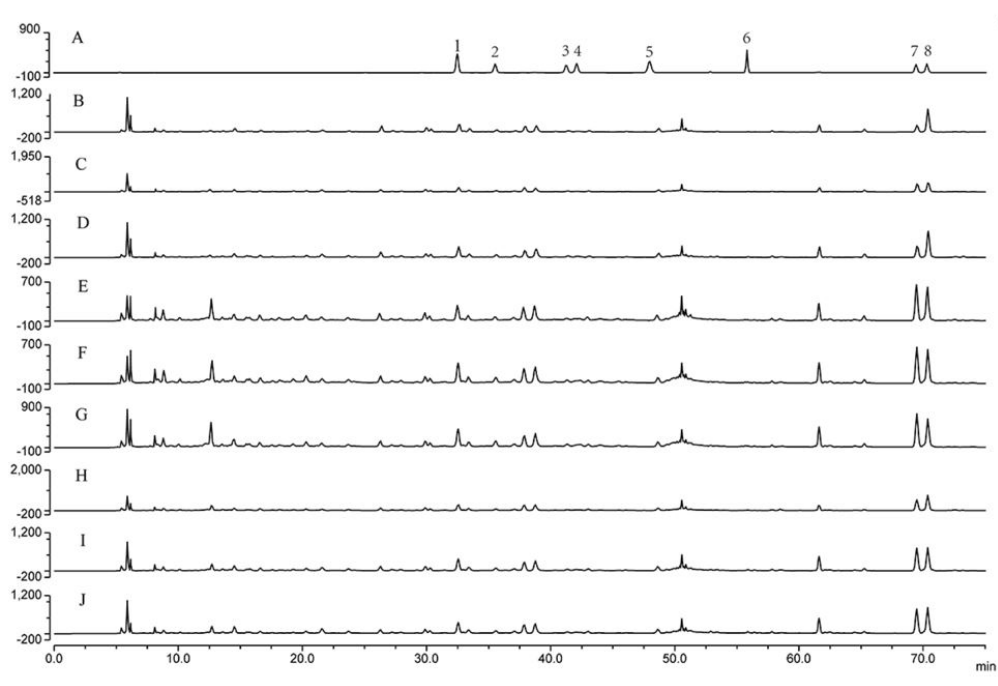

a
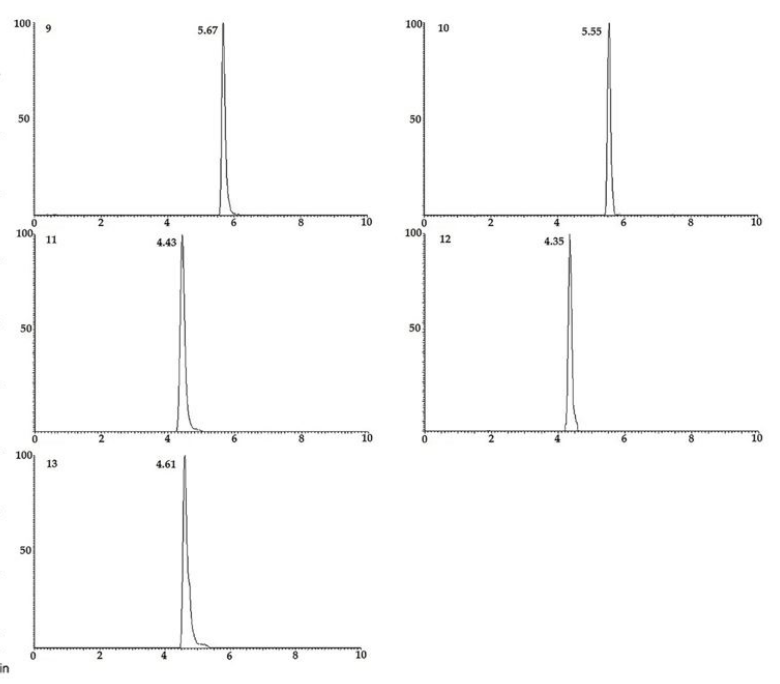

b

Figure 2. (a) is the result of HPLC analysis: rutin (1), quercetin-3-O- $\beta$-glucoside (2), kaempferol-3-O- $\beta$-D-glucopyranoside (3), isorhamnetin3-O-glucoside (4), myricetin (5), apigenin (6), isoginkgetin (7), ginkgetin (8). A-J are the results of part of origin. (b) is the standard diagram of UPLC-MS/MS analysis: ginkgolide A (9), ginkgolide B (10), ginkgolide C (11), ginkgolide J (12), and bilobalide (13). 
Li et al.

Table 3. ABTS free radical scavenging ability of $G$. biloba leaves from 14 different places $(\%)(\mathrm{n}=3, x, - \pm s)$.

\begin{tabular}{cccccccc}
\hline Origin & $1(\mathrm{mg} / \mathrm{mL})$ & $0.5(\mathrm{mg} / \mathrm{mL})$ & $0.25(\mathrm{mg} / \mathrm{mL})$ & $0.125(\mathrm{mg} / \mathrm{mL})$ & $0.06(\mathrm{mg} / \mathrm{mL})$ & $0.03(\mathrm{mg} / \mathrm{mL})$ & $\mathrm{IC}{ }_{50}(\mathrm{mg} / \mathrm{mL})$ \\
\hline 1 & $90.31 \pm 0.76$ & $78.98 \pm 1.28$ & $48.48 \pm 1.85$ & $37.25 \pm 1.78$ & $26.30 \pm 1.96$ & $12.56 \pm 2.11$ \\
2 & $82.44 \pm 2.59$ & $75.47 \pm 0.29$ & $46.81 \pm 0.78$ & $32.40 \pm 1.31$ & $19.98 \pm 1.48$ & $4.01 \pm 0.05$ \\
3 & $93.50 \pm 0.82$ & $91.51 \pm 0.87$ & $66.89 \pm 1.53$ & $60.02 \pm 1.75$ & $37.48 \pm 1.98$ & $26.99 \pm 1.29$ \\
4 & $96.22 \pm 1.20$ & $70.90 \pm 2.66$ & $60.20 \pm 2.89$ & $40.20 \pm 1.57$ & $33.74 \pm 1.21$ & $21.16 \pm 1.78$ & 0.379 \\
5 & $98.33 \pm 1.54$ & $76.43 \pm 2.25$ & $58.01 \pm 1.94$ & $43.37 \pm 1.78$ & $30.54 \pm 1.04$ & $22.18 \pm 1.27$ \\
6 & $85.07 \pm 2.45$ & $67.52 \pm 2.11$ & $51.11 \pm 2.50$ & $42.41 \pm 1.70$ & $30.59 \pm 1.92$ & $24.11 \pm 1.06$ \\
7 & $90.47 \pm 0.23$ & $85.97 \pm 2.91$ & $55.01 \pm 1.47$ & $40.07 \pm 1.26$ & $31.98 \pm 2.26$ & $17.74 \pm 0.85$ \\
8 & $86.06 \pm 1.42$ & $71.31 \pm 1.51$ & $53.40 \pm 1.37$ & $31.23 \pm 1.30$ & $33.58 \pm 1.09$ & $26.14 \pm 0.90$ & 0.131 \\
9 & $76.22 \pm 1.70$ & $62.12 \pm 1.61$ & $35.33 \pm 1.04$ & $35.54 \pm 2.02$ & $24.40 \pm 1.08$ & $13.48 \pm 1.86$ & 0.237 \\
10 & $96.66 \pm 2.37$ & $88.21 \pm 2.50$ & $62.48 \pm 2.92$ & $39.49 \pm 2.34$ & $37.54 \pm 1.20$ & $16.70 \pm 5.08$ \\
11 & $86.35 \pm 1.87$ & $79.39 \pm 1.67$ & $69.71 \pm 1.65$ & $40.92 \pm 2.02$ & $25.70 \pm 1.89$ & $18.96 \pm 0.19$ & 0.461 \\
12 & $97.47 \pm 1.93$ & $87.65 \pm 1.40$ & $62.40 \pm 0.90$ & $44.36 \pm 1.33$ & $28.43 \pm 1.71$ & $14.67 \pm 1.90$ & 0.196 \\
13 & $80.66 \pm 2.08$ & $62.47 \pm 1.84$ & $48.19 \pm 2.67$ & $39.85 \pm 2.25$ & $29.86 \pm 0.89$ & $9.54 \pm 1.01$ & 0.262 \\
14 & $95.81 \pm 1.85$ & $75.12 \pm 1.18$ & $53.08 \pm 2.00$ & $43.33 \pm 0.46$ & $30.12 \pm 1.24$ & $14.99 \pm 2.21$ & 0.386 \\
\hline
\end{tabular}

Table 4. The correlation of the 13 chemical compounds and the activities in G. biloba leaves.

\begin{tabular}{lccc}
\hline \multicolumn{1}{c}{ Compounds } & Correlation & Compound & Correlation \\
\hline Rutin & -0.518 & Ginkgetin & $-0.703^{* *}$ \\
Quercetin-3-O- $\beta$-glucoside & -0.426 & Ginkgolide A & -0.215 \\
Kaempferol-3-O- $\beta$-D-glucopyranosid & 0.069 & Ginkgolide B & -0.375 \\
Isorhamnetin-3-O-glucoside & -0.079 & Ginkgolide C & -0.20 \\
Myricetin & -0.125 & Ginkgolide J & -0.329 \\
Apigenin & 0.035 & Bilobalide & -0.074 \\
Isoginkgetin & $-0.761^{* *}$ & & \\
\hline
\end{tabular}

${ }^{* *} P<0.01$.

ginkgetin are $98 \pm 1.83$ and $94 \pm 1.73$, respectively, in $0.2 \mathrm{mg} / \mathrm{mL}$, isoginkgetin and ginkgetin are $93 \pm 2.48$ and $99 \pm 1.59$, respectively. Therefore, these concentrations were selected for further experiments.

\subsection{Effect of isoginkgetin and ginkgetin on MMP-1 levels in $\mathrm{HDFs}$}

Isoginkgetin and ginkgetin at 0.1 and $0.2 \mathrm{mg} / \mathrm{mL}$ significantly reduced MMP-1 levels in HDFs $(P<0.01$; Figure 3 A). PCR analysis showed that isoginkgetin and ginkgetin significantly $(P<0.01)$ inhibited $M M P 1$ expression (Figure $3 \mathrm{~B})$.

\section{Discussion}

The widespread distribution of G. biloba and research focused on exploring the therapeutic value of natural medicine therapeutic agents are continuously developing, which have together promoted research on G. biloba leaves (Gong et al., 2008; Guo et al., 2019). Although many studies have been conducted on the antioxidant effects of G. biloba leaves in recent years, there is still a lack of research on the detailed antioxidant properties and mechanisms, especially with respect to identification of the most potent active ingredients. Further clarifying the compounds in $G$. biloba leaves that are most relevant for its antioxidant activity is of great significance for promoting the development of $G$. biloba-related industries. The purpose of the present study was therefore to confirm the active ingredients in G. biloba leaves with the strongest relation to its antioxidant activity, and to provide a scientific basis for the quality control of antioxidants in G. biloba leaves. Correlation analysis of the antioxidant activity of G. biloba leaves and active ingredients was used to identify the compounds significantly related to the antioxidant activity of G. biloba leaves collected across 14 disparate regions in China, and the activity of the relevant analysis results were verified by ELISA and PCR. These methods showed that isoginkgetin and ginkgetin have obvious antioxidant activity.

Quantitative analyses of eight flavonoids and five lactones in the 14 samples showed that the active ingredient and antioxidant properties of $G$. biloba leaves from different origins were significantly different, and flavonoids were not detected in samples from certain origins. To ensure that acceptable standards are met, we only collected the leaves of 4-7-year-old trees from August to October (Du et al., 2000). Differences in geographical environments and climatic conditions, including precipitation 


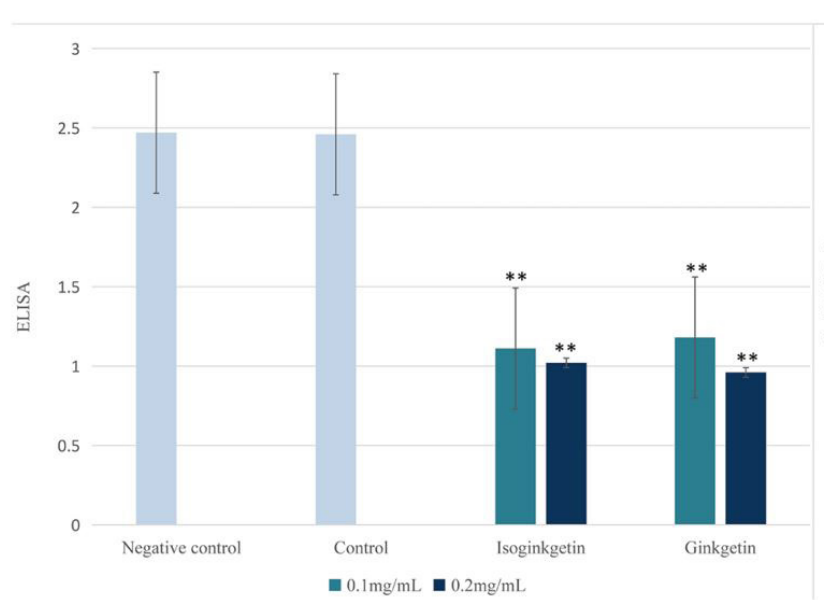

A

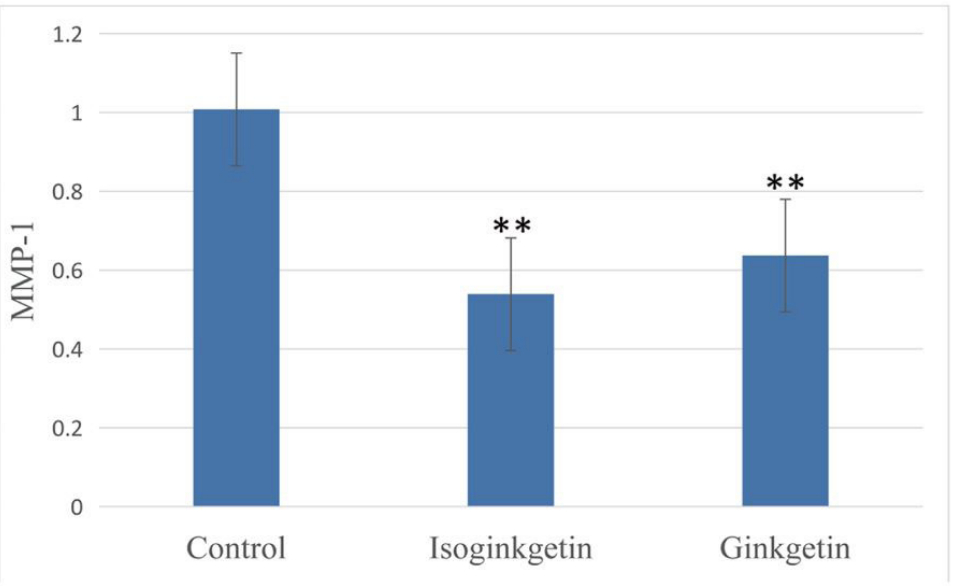

B

Figure 3. (A) is the results of ELISA on effects of two components on the secretion of MMP-1 from fibroblasts $(\mathrm{n}=3, x,- \pm \mathrm{s})$, ${ }^{* *} P<0.01$; (B) is the results of PCR effects of two components on the secretion of MMP-1 from fibroblasts $\mathrm{n}=3, x,- \pm \mathrm{s}$ ), ${ }^{* *} P<0.01$.

and altitude, in different cultivation regions of China lead to variations in the active components of G. biloba leaves, which ultimately affect the quality (Lin et al., 2019; Yao et al., 2017). This uncontrolled distribution creates a considerable challenge to conventional quality control strategies that currently depend on morphological characteristics, making the qualitative or quantitative determination of one or several bioactive marker components important (Xie et al., 2010).

Strong negative correlations between isoginkgetin or ginkgetin and antioxidant activity were identified, which was based on the $\mathrm{IC}_{50}$ value. This indicated that a higher content of these two flavonoids in G. biloba leaves results in stronger antioxidant activity. In general, peroxidation is one of the main factors leading to an increase in MMP levels. The ELISA results showed that isoginkgetin and ginkgetin at 0.1 and $0.2 \mathrm{mg} / \mathrm{mL}$ significantly reduced MMP-1 levels in HDFs at the protein and gene levels. Collectively, these results indicate that these two flavonoids are the two most active ingredients with strong relations to the antioxidant activity of G. biloba leaves. Therefore, when formulating the quality standards of G. biloba leaves, if the antioxidant effect is the main therapeutic effect, attention should be paid to the content of these two compounds.

Notably, the quantitative analysis showed that G. biloba leaves from Xinjiang province, Xuzhou (Jiangsu province), and Hebei province had higher levels of isoginkgetin and ginkgetin than leaves collected from other areas. Therefore, G. biloba growing in these locations should be prioritized as the raw materials of medicinal products when being applied for antioxidant effects.

Botanical medicines are a combination of multiple compounds, including those that play a pharmacological role (Wang et al., 2018); however, it is important to clarify the most relevant active ingredients contributing to the pharmacological effects. Although previous studies have reported the antioxidant activity of $G$. biloba leaves as well as the antioxidant activities of isoginkgetin and ginkgetin, the most relevant active ingredients contributing to the antioxidant activity of G. biloba leaves have not been scientifically studied to date. The present research can therefore provide a scientific basis for the development of the ginkgo leaf medicine industry. Moreover, these two compounds are also present in Dioon edule Lindl. leaves, and ginkgetin is present in Taxus wallichiana Zucc. and some Selaginella plants (Liu et al., 2002; Moawad \& Amir, 2016; Qiu et al., 1989). Accordingly, our findings can also provide new directions for the pharmacological research of other plants.

\section{Conclusions}

Through correlation analysis of the antioxidant activity of G. biloba leaves and their active ingredients in different regions, and the use of ELISA and PCR to verify the correlation analysis results, we identified isoginkgetin and ginkgetin as the likely main active compounds in G. biloba with antioxidant and MMP-1 inhibitory activity. Therefore, monitoring the levels of these two compounds might improve estimating the quality of $G$. biloba leaf raw material. The results of this study provide a scientific basis and reference for the application of G. biloba leaf as an antioxidant raw material. The levels of these components were the highest in the materials collected from Xinjiang province, Xuzhou, and Hebei province, which indicates that these regions should be prioritized for obtaining G. biloba leaf materials with superior quality.

\section{References}

Chen, C. C., Chiang, A. N., Liu, H. N., \& Chang, Y. T. (2014). EGb761 prevents ultraviolet $\mathrm{B}$-induced photoaging via inactivation of mitogen-activated protein kinases and proinflammatory cytokine expression. Journal of Dermatological Science, 75(1), 55-62. http:// dx.doi.org/10.1016/j.jdermsci.2014.04.001. PMid:24802711.

Du, A. Q., Wang, X. R., Zhou, Z. H., Xu, F. M., \& Xia, C. D. (2000). Concentration of Ginkgo flavonoids glycosides in Ginkgo biloba leaves in ralation to the various season and tree^ $\mathrm{s}$ age. Natural Product Research Development, 12(2), 49-51. http://dx.doi.org/10.3969/j.issn.1001-6880.2000.02.012.

Du, G. L., Chen, W. Y., Li, X. N., He, R., \& Feng, P. F. (2017). Induction of MMP- 1 and- 3 by cyclical mechanical stretch is mediated by IL- 6 in cultured fibroblasts of keratoconus. Molecular Medicine Reports, 15(6), 3885-3892. http://dx.doi.org/10.3892/mmr.2017.6433. PMid:28393195. 
Editorial Committee of Chinese Flora of the Chinese Academy of Sciences. (1978). The flora of China (Vol. 7). Beijing, China: Science Press.

Gong, W., Chen, C., Dobeš, C., Fu, C. X., \& Koch, M. A. (2008). Phylogeography of a living fossil: pleistocene glaciations forced Ginkgo biloba L. (Ginkgoaceae) into two refuge areas in China with limited subsequent postglacial expansion. Molecular Phylogenetics and Evolution, 48(3), 1094-1105. http://dx.doi.org/10.1016/j. ympev.2008.05.003. PMid:18554931.

Guo, Y., Lu, Y., El-Kassaby, Y. A., Feng, L., Wang, G., \& Wang, T. (2019). Predicting growth and habitat responses of Ginkgo biloba L. to climate change. Annals of Forest Science, 76(4), 101. http://dx.doi. org/10.1007/s13595-019-0885-0.

Kingsley, N. O., Ikechukwu, U. K., Chinwe, O. A. N., \& Okechukwu, O. D. (2019). Investigation of the antioxidant activity of aqueous and ethanol leaf extracts of ginkgo biloba from South-East Nigeria. International Journal of Plant Science and Ecology, 5, 31-36.

Lee, M. H., Lin, Y. P., Hsu, F. L., Zhan, G. R., \& Yen, K. Y. (2006). Bioactive constituents of Spatholobus suberectus in regulating tyrosinaserelated proteins and mRNA in HEMn cells. Phytochemistry, 67(12), 1262-1270. http://dx.doi.org/10.1016/j.phytochem.2006.05.008. PMid:16782143.

Lin, L. Z., Chen, P., Ozcan, M., \& Harnly, J. M. (2008). Chromatographic profiles and identification of new phenolic components of Ginkgo biloba leaves and selected products. Journal of Agricultural and Food Chemistry, 56(15), 6671-6679. http://dx.doi.org/10.1021/jf800488x. PMid:18598036.

Lin, Y., Lou, K., Wu, G., Wu, X., Zhou, X., Feng, Y., Zhang, H., \& Yu, P. (2019). Bioactive metabolites in of Ginkgo biloba leaves: variations by seasonal, meteorological and soil. Brazilian Journal of Biology = Revista Brasileira de Biologia. http://dx.doi.org/10.1590/15196984.220519. PMid:31800764.

Liu, H. Q., Lin, R. C., Feng, F., \& Dang, H. Q. (2002). Determination of biflavones from selaginella by HPLC. Yaowu Fenxi Zazhi, 22(5), 392-394.

Moawad, A., \& Amir, D. (2016). Ginkgetin or isoginkgetin: the dimethylamentoflavone of Dioon edule Lindl. leaves. European Journal of Medicinal Plants, 16(3), 1-7. http://dx.doi.org/10.9734/EJMP/2016/28560.

Qiu, J., Chen, X., Netrusov, A., Zhou, Q., Guo, D., Liu, X., He, H., Xin, X., Wang, Y., \& Chen, L. (2017). Screening and identifying antioxidative components in Ginkgo biloba pollen by DPPH-HPLC-PAD coupled with HPLC-ESI-MS2. PLoS One, 12(1), e0170141. http://dx.doi. org/10.1371/journal.pone.0170141. PMid:28095510.
Qiu, L.F., Lian, M., Ma, Z.W., \& He, G. (1989). Biflavones of Taxus wallichiana Zucc. Journal of Integrative Plant Biology, 1(1), 56-58.

Shao, J., Wang, B., Chen, X., \& Duan, C. (2003). Advanced research on pharmacology value of the extracts of Ginkgo biloba leaves. Journal of Chongqing University, 26, 130-134. https://10.3969/j.issn.1000582X.2003.01.034.

Wang, X., Gong, X., Zhang, H., Zhu, W., Jiang, Z., Shi, Y., \& Li, L. (2020). In vitro anti-aging activities of ginkgo biloba leaf extract and its chemical constituents. Food Science and Technology (Campinas), 40(2), 476-482. http://dx.doi.org/10.1590/fst.02219.

Wang, Y., \& Yang, Y. F. (2001). Research progress on the pharmacological effects and mechanism of Ginkgo biloba leaf. The Chinese Journal of Modern Applied Pharmacy, 18, 1-4. https://10.3969/j.issn.10077693.2001.01.002.

Wang, Z., Chen, Y. Y., Zhang, Y. Y., Wu, P., \& Wang, J. (2018). Problems and solutions in study of multi-component and multi-target mechanism of action of traditional chinese medicine. Zhongguo Shiyan Fangjixue Zazhi, 24, 1-6. http://dx.doi.org/10.13422/j.cnki. syfjx.2018050001.

Xie, P. S., Yan, Y. Z., Guo, B. L., Lam, C., Chui, S., \& Yu, Q. X. (2010). Chemical pattern-aided classification to simplify the intricacy of morphological taxonomy of Epimedium species using chromatographic fingerprinting. Journal of Pharmaceutical and Biomedical Analysis, 52(4), 452-460. http://dx.doi.org/10.1016/j.jpba.2010.01.025. PMid:20144519.

$\mathrm{Xu}$, H. T., \& Zhang, J. Y. (2017). Correlations between antioxidant activities and contents of total flavonoids and total phenols of four extracts from Nervilia fordii. Zhongchengyao, 39(1), 121-125. http:// dx.doi.org/10.3969/j.issn.1001-1528.2017.01.024.

Yao, J. B., Du, X., Jin, H. H., Fang, L., Min, H., Qiao, H. X.,Wang, R.W., \& Kuchta, K. (2017). Seasonal variability of genistein and 6-hydroxykynurenic acid contents in Ginkgo biloba leaves from different areas of China. Natural Product Communications, 12(8). https://doi.org/10.1177/1934578X1701200823.

Yao, X., Zhou, G., Tang, Y., Guo, S., Qian, Y., Jin, C., Qin, Y., Qian, D. W., \& Duan, J. A. (2014). UPLC-PDA-TOF/MS coupled with multivariate statistical analysis to rapidly analyze and evaluate Ginkgo biloba leaves from different origin. Drug Testing and Analysis, 6(3), 288-294. http://dx.doi.org/10.1002/dta.1477. PMid:23666896. 